\title{
EL INTERTEXTO COMO PRINCIPIO CONSTRUCTIVO \\ EN LOS CUENTOS DE AZUL... Y SU PROYECCION \\ EN LA NUEVA NARRATIVA LATINOAMERICANA
}

\author{
POR \\ IVAN URIARTE \\ Universidad de Nicaragua
}

1. A casi un siglo de distancia, la crítica sobre $A z u l \ldots$ ha progresado muy lentamente. Desde la inicial consagración de Valera como «galicismo mental» a las precisiones de Watland y Mapes (rastreando los nexos de la obra con el simbolismo y el Parnaso), la génesis erudita de Marasso y las agudas observaciones de Lida sobre el quehacer literario de Darío como narrador, sólo las investigaciones de Noel Salomón sobre los chilenismos en $A z u l . .$. y la actitud crítico-social que el breve volumen alcanza, parecen, en realidad, agregar algo nuevo que se desvía de aquella oficial consagración de Valera.

En términos generales, la creación de Rubén Darío plantea un problema específico, el cual, precisamente, se inicia con $A z u l . .$. , que la crítica dariana todavía no ha abordado con el rigor que la teoría literaria - la Poética o la Semiótica- contemporánea requiere. Es encomiable, por otra parte, que las revalorizaciones y cuestionamientos al Modernismo y Dario han sido hechos desde una perspectiva sociologizante - Ramao althusseriana - como la de la franco-mexicana Françoise Pérus.

Estas notas tienen por objeto mostrar la proyección de ese señero libro en la nueva literatura latinoamericana, la cual parece emerger solamente de una gama de influencias que los críticos no cesan de combinar - Joyce, Kafka, Eliot, Pound, Faulkner-, olvidando, quizás, que algunos de esos deslumbrantes procedimientos, descubiertos en aquellos autores, ya habían sido empleados por más de un modernista.

En términos concretos, ¿qué significado puede tener hoy $A z u l \ldots$, a casi un siglo de distancia? ¿Es que aquella tan celebrada novedad de la introducción del cuento parisiense a lo Catulle Mendès, Gautier, Armand Sylvestre o el "Cabinet de 1'Extrême Orient» de Edmond Goncourt tiene sentido todavía? Veamos. Con la publicación de $A z u l . .$. , Darío no sólo 
inaugura una nueva prosa en lengua española, sino que también inicia, con lucidez y plena conciencia artística, un procedimiento que sentará las bases de un sistema literario que ha encontrado su culminación y grandes logros con la instauración de la nueva literatura latinoamericana. Me refiero, específicamente, al uso del intertexto, que Darío no sólo sistematiza, sino que lo convierte en el principio constructivo literario de su obra creadora. Todo aquello que desconcertaba a Valera, bajo la asombrosa confirmación de que Darío no imitaba a nadie y que había que llamarlo una «rara quintaesencia», no era más que la mise en cause del texto como propiedad, o sea, su expropiación en nombre de un nuevo texto.

Antes de abordar la problemática que la intertextualidad plantea en la obra creadora dariana -en Azul... específicamente y su proyección en el quehacer literario de la actual literatura hispanoamericana-, recordemos brevemente la teoría del intertexto.

2. La intertextualidad, en su sentido más amplio, es un rectrso literario que, para sólo limitarnos a la lengua española, tiene su más conocido precedente en el Don Quijote de Cervantes, cuando, en la segunda parte, Cervantes aclara que la historia del caballero de la Mancha la encontró en un manuscrito árabe en Alacaná, «escrita por Hamete Benengeli, historiador arábigo». Así, pues, en cada época, ya se trate de épocas literarias tan diversas como la de Petronio, Rabelais, Cervantes o Lautréamont, "periódicamente en la historia de la literatura - como nos aclara Laurent Jenny - aparecen textos que arremeten contra el monolitismo de sentido y escritura, preñados por la exuberancia y carga cultural de textos antecedentes».

Para mejor comprender el hecho intertextual contemporáneo recordemos, con André Topia, que el sistema de la cita clásica obedece a dos prohibiciones: a) no modificar el texto citado; $b$ ) prohibición de atentar contra la jerarquía que sitúa al texto en un estatuto de simple auxiliar del texto principal. E1 procedimiento intertextual, entonces, consiste en la supresión de comillas en el texto, introduciendo el estilo indirecto y libre y con ello un cambio de niveles en la enunciación; esta transformación opera como una compuerta que permite la entrada de todo discurso extraño al texto que se está elaborando. Literalmente, pues, se trata de un collage intertextual, donde la cola — parodiando a Max Ernst- no hace el intertexto. Las consecuencias serán, por un lado, la utilización de determinado texto $y$, por otro, una nueva realización (porque a menudo el texto original es modificado) que viene a integrarse al texto en progresión, el cual es contaminado y puesto en nueva perspectiva.

De esta manera, el estatuto del intertexto se expande en un movimien- 
to que va desde la copia y la transcripción hasta la reescritura misma, pasando por los diferentes grados de la parodia y la reactivación.

3. Es conveniente ahora, aunque sólo sea al pasar, precisar los niveles de intertextualidad que Darío manipula e inserta en Azul... A partir de las investigaciones de Mapes y Marasso, podemos deducir que Darío no juega con inserciones de valor prosódico marcado (oculta la presencia del texto nuevo) y, por tanto, provoca en el lector un trabajo de identificación y de interpretación del mismo. Señalemos ya que el intertexto dariano combina una variedad de textos a la vez, tal como lo hace en «El velo de la reina Mab», lo cual complica enormemente detectar la frecuencia de transposición matricial y el grado selectivo que se opera en el texto:

a) en primer lugar, la raíz shakespeariana que le sugiere el cuento se convierte en una variante de la descripción hecha en el acto IV de Romeo y Julieta;

b) esa variante está realizada a partir de una reactivación intertextual de la «Dernière fée» de Catulle Mendès, que le proporciona, parcialmente, l'histoire;

c) de Charles Perrault y del mismo Mendès ( $\mathrm{E}$ l linchamiento de Puck») tomará el tono de cuentos de hadas, el cual desvirtuará con el planteamiento de la problemática del artista frente a la sociedad, dada a través del discurso del escultor, el poeta, el músico y el pintor. Pero la operación intertextual va más allá, precisamente por los nexos que guarda con el «Coloquio de los perros» de Cervantes y otros textos, como bien lo señala Marasso.

Caso similar sería el de «La ninfa», donde Darío, atentando contra la estructura del cuento parisiense, introduce un tipo de narración que juega con alusiones eruditas, que se remonta al P. Nieremberg, Lope de Vega, Vitoria, Alciato y otros.

En «El palacio del sol», partiendo de la cadena literaria que Darío encontró en el Nouveau Décameron, transforma el relato matriz («Le jardin de jeunes âmes») para abordar, con malicia y fina ironía, la educación sexual que los adolescentes deben tener, remontándose a textos que abordan esa misma problemática, como El acero de Madrid de Lope de Vega y $E l$ sí de las niñas de Moratín.

Los otros textos claves de $A z u l . .$. , «E1 rey burgués» y «La canción del oro», presentan un grado de ensamblaje intertextual que va más allá de la reactivación y la escritura y que introduce procedimientos sustitutivos y de reconstitución del intertexto, los cuales, para dar una referencia más contemporánea, son el principio de construcción literaria del Canto general de Neruda. 
Podemos confirmar con estos ejemplos la complejidad del trabajo dariano, la cuidadosa mise en cause de textos para lograr un cambio de lenguaje en la narrativa de lengua española en un momento de anquilosamiento de ésta, la cual Darío revitaliza no sólo a través de la expropiación de la cadena literaria, como hemos visto, sino también acudiendo a diversos niveles dialectales del español, que en lo concerniente a $A z u l . .$. está sutilmente preñado de chilenismos.

Después de haber abordado los niveles de intertextualidad en la narrativa de $A z u l . .$. , refirámonos a otro tipo de intertextualidad, que Darío empleará tan sistemáticamente como la intertextualización de la cadena literaria. Me refiero a otra modalidad de este procedimiento propuesta por Lotman, y es la del intertexto icónico, que según él conforma un sistema de narración que es una interna transposición de elementos. De sobra sabemos cómo Darío reactiva en sus textos una iconografía que se remonta a los clásicos, prerrománticos, el siglo xvıII, para extasiarse en el xix: Watteau, Delacroix, Doré, Callot, Millet, Veber, para sólo mencionar algunos.

Esta apropiación del texto introduce, a su vez, cambios ortográficos en la lengua (azur, harmonía, kalisto, makheda...) que plantean al lector un juego etimológico de identificaciones, que sugieren, además, el origen del intertexto.

Estudiar los niveles y modalidad de intertextualización que Darío realiza con plena conciencia artística es un trabajo que nos revelaría (a partir de un minucioso cotejo con los textos matrices) el poder de ensamblaje intertextual que el poeta nicaraguiense inicia en $A z u l \ldots$ y que desarrolla posteriormente, con dominio y gran maestría, en Prosas profanas y Cantos de vida y esperanza. Ahora bien, ese quehacer intertextual genera una estructura literaria propia en cada obra. Si en $A z u l . .$. , además del claro planteamiento sociohistórico que nos hace - la inconformidad del artista frente a una estructura de poder que lo excluye y margina-, es un ensayo sobre las ideas estéticas del modernismo, y también la proposición de una nueva lectura e interpretación de la cadena literaria, en Prosas profanas el arduo trabajo de intertextualización genera una estructura que nos confronta al texto como máscara y carnavalización del mundo, en e1 sentido que Bajtin lo propuso en sus investigaciones sobre Rabelais.

4. La proyección de $A z u l \ldots$ sobre la nueva literatura latinoamericana no ha sido considerada todavía. Se ha hablado de Darío como renovador de la lengua, como un maestro, pero en realidad no se ha confrontado el procedimiento literario fundador, con el cual, como su quehacer lite- 
rario lo revela, inicia la transformación de una literatura que ya tenía otro precursor: Mallarmé.

Es extraño, por otra parte, el silencio y la incomprensión de la labor pionera de Darío. Jorge Luis Borges, en un ensayo sobre Leopoldo Lugones, en 1955, observaba, a propósito de $A z u l . .$. , lo siguiente: «De este libro, cuya importancia histórica es innegable, quizá lo único que aún sobreviva sea algún soneto como el dedicado a Walt Whitman.» Es probable que Borges pensara en el verso «Su alma del infinito parece espejo», que de un golpe nos transporta a los laberintos internos de $E l$ hacedor, libro, casualmente, no exento de lo que $A z u l . .$. había ya propuesto en su tiempo: prosa y verso no sólo requieren igual trabajo artístico, sino que también continúan el mismo discurso.

Que esta negación y esta coincidencia nos sirvan para precisar, dentro. del breve espacio que nos resta, la presencia de la narrativa de Azul... en la literatura latinoamericana de hoy.

El breve manojo de cuentos de $A z u l \ldots$ nos parece un texto fundador en todo el sentido de la palabra. Si hemos señalado en ellos la presencia del intertexto es porque precisamente este procedimiento, que comienza a hacerse sentir en las escuelas de vanguardia europeas, dinamiza y fecunda toda una corriente de la poesía y la narrativa latinoamericana del siglo xx. Pero Darío, como todo precursor, ya lo había convertido en el principio constructivo literario de su obra de creación, iniciándolo precisamente en $A z u l \ldots$

Agreguemos: de este procedimiento literario, que funciona como un connotador artístico, se desprenden otras cualidades formales y estructurales. Trataremos de precisar, primero, la incidencia del intertexto en el quehacer literario de nuestra actual literatura, para luego referimos a las cualidades formales y a las estructuras.

Jorge Luis Borges es, sin lugar a dudas, el autor latinoamericano que ha llevado el intertexto a su culminación, combinando todas las doctrinas filosóficas y literaturas de Oriente y Occidente, hasta inventar el intertexto mismo con la introducción de textos apócrifos. Ni Borges ni nadie puede negar que el procedimiento intertextual tiene su primer antecedente, en tanto que connotador artístico funcionando dentro de un sistema literario determinado, en los cuentos de Azul... Además, en «La ninfa» ya encontramos el tono erudito que Borges combinará hasta la saciedad: «Los sátiros y los faunos, los hipocentauros y las sirenas han existido como la salamandra y el Ave Fénix.» «El perro gigantesco que vio Alejandro, alto como un hombre, es tan real como la araña Kraken.» «Afirma San Jerónimo que en tiempo de Constantino Magno se condujo a Alejandría un sátiro vivo, siendo conservado su cuerpo cuando murió.» 
«Y Filegón Traliano... afirma la existencia de dos clases de hipocentauros: una de ellas como un elefante.» Estas citas, ¿no nos recuerdan, inclusive, el Manual de zoología fantástica del propio Borges?

Este mismo procedimiento intertextual, como dijimos, genera cualidades formales y estructurales, con incidencia y proyección en el más complejo trío de nuestra literatura: Borges, Cortázar y Paz. Jaime Alazraki, a propósito de estos tres autores, se ha referido al ensayo como narración y viceversa, que ya Darío había iniciado en $A z u l . .$. Y lo que Alazraki afirma es válido para ese señero manojo de cuentos: «Como la ficción que habla a través de una voz narrativa, el ensayo dilucida a través de una voz reflexiva.»

Para evitar equívocos, notemos que el intertexto, como principio constructivo en literatura, tiene sus propias modalidades en cada sistema literario. Sin lugar a dudas, con las escuelas de vanguardia se inició un nuevo sistema literario donde aquel principio constructivo que Darío inició en nuestras letras ha variado, porque han variado los contextos y el entorno, las idiosincrasias y preferencias. Pero lo importante es que ese procedimiento que Darío inicia dinamiza hoy diversas tendencias de nuestra literatura, que incluye autores tan diversos como Neruda, Paz, Borges, Roberto Juarroz, Carlos Martínez Rivas, Ernesto Cardenal, Juan José Arreola, Lezama Lima, Carpentier, Roque Dalton. Y, precisamente por ello, es innegable la presencia del autor de $A z u l \ldots$ en sus obras.

Hay un narrador que deliberadamente no hemos incluido en esta incompleta lista, porque sus nexos con el autor de $A z u l \ldots$ nos parecen más claros y estrechos que con ningún otro narrador contemporáneo de la América nuestra. Nos referimos a Gabriel García Márquez. La prosa del autor de Cien años de soledad no podría explicarse sin el mágico extrañamiento del referente que Darío inició en los cuentos de Azul... Un riguroso paralelo entre ambas prosas narrativas nos revelaría un similar trabajo de orfebrería: la prosa narrativa debe ser elaborada con el rigor del verso y conservar la fluidez y plasticidad que le corresponde. Obviemos la intensidad intertextual de Cien años de soledad (que va de La Biblia, Las mil y una noches y La princesa de Babilonia a la cadena extraliteraria de raíz popular) para recordar que no es una coincidencia que ésta se inicie con una referencia doblemente dariana que nos remonta a aquella «tarde que su padre lo llevó a conocer el hielo», al coronel Aurelio Buendía, lo cual es un intertexto de la Autobiografía de Dario, quien, no por puro azar, tuvo como padre adoptivo a otro coronel: el coronel Ramírez. ¿Y qué decir de todas las alusiones y referencias intertextualizadas en Darío en El otoño del Patriarca?

La relación $A z u l . .$. -nueva literatura latinoamericana va más allá de 
estos atisbos, porque la obra precursora nunca termina de acosarse, de agotar sus posibilidades de expansión y dilatación.

Concluyo: $A z u l \ldots$ es el vivero inicial de las corrientes, tendencias y procedimientos (como la intertextualidad) de la nueva narrativa latinoamericana. El manejo del cuento de hadas, colindando con la farsa, cubre un campo que va de la parodia al «realismo mágico» y a lo «real maravilloso». «La ninfa» y «La canción del oro» prefiguran un empleo de la. erudición que hoy reaparece como discurso constante en algunos de nuestros mejores narradores. «E1 fardo» anticipa un delicado tipo de literatura social que, partiendo de la simple anécdota, va más allá de la metáfora misma. En «El rubí», la denuncia de la emergente sociedad de consumo alejando al hombre de la naturaleza transmuta el mito en parábola.

En suma, cada cuento de $A z u l \ldots$ presenta una problemática que sobrepasa los límites de la bibliografía, la exégesis, la edición crítica. Ahora que se acercan los cien años de la publicación de $A z u l . .$. la nueva crítica latinoamericana tiene que responder a ese desafío. 
